\title{
STEM CELLS FOR ENHANCING RECOVERY AFTER STROKE: A REVIEW
}

Tim England, ${ }^{1}$ MRCP(UK); Paul Martin, ${ }^{2}$ PhD; Philip M W Bath, ${ }^{1}$ FRCPath, FRCP

Stroke Trials Unit, ${ }^{1}$ Institute of Neuroscience, University of Nottingham, UK; and Institute for Science and Society, ${ }^{2}$ School of Social Sciences, University of Nottingham, Nottingham UK

Correspondence: Professor Philip Bath

Division of Stroke Medicine

University of Nottingham

City Hospital Campus

Nottingham NG5 1PB

Tel: 01158231768

Fax: 01158231767

Email: Philip.bath@nottingham.ac.uk

Key words: stem cells, ischaemic stroke, granulocyte-colony stimulating factor

Abstract: 104 words

Text: 5196 words (not including references or tables)

\section{ABSTRACT}

The potential application for stem cell therapy is vast and its development for use in ischaemic stroke is still at its infancy. Access to stem cells for research is contentious but various sources are obtainable from both animals and humans. Despite a limited understanding of their mechanisms of action, clinical trials assessing stem cells in human stroke have been performed. Trials are also underway evaluating haematopoietic precursors mobilised with granulocyte-colony stimulating factor, an approach offering an autologous means of administrating stem cells for therapeutic purposes. This review summarises current knowledge in regard of stem cells and their potential for helping improve recovery after stroke. 


\section{INTRODUCTION}

Stroke is the third leading cause of death worldwide and is devastating to both patients and carers. More than half of all stroke survivors are left dependent on others for everyday activities (1). Each year there are 110,000 first strokes and 30,000 recurrent strokes in the United Kingdom; 10,000 strokes occur in people younger than 65 and 60,000 people die of stroke. More than five per cent of NHS and social service resources are consumed by stroke patients (2). Finding an effective acute intervention for this burden, which is present worldwide, is proving challenging: aspirin has a wide utility but modest efficacy, and alteplase the converse; anticoagulation has proven ineffective (3) and various approaches with neuroprotection remain under investigation (4). In fact, with the exception of aspirin, thrombolytic therapy and hemicraniectomy, clinical management is primarily based on supportive care in a stroke unit (5-7).

One potentially important area of development in the treatment of stroke is the use of stem cells to enhance recovery. The definition of a stem cell continues to evolve as more knowledge is gained on the subject. It currently requires demonstration of two properties: the capacity for self-renewal and the ability to differentiate into multiple cell types (potency) (8). A progenitor cell also has these characteristics but has a more restricted potential, i.e. it can only differentiate into a limited number of cell types and has a reduced capacity for self-renewal (8). Stem cell transplant trials are already underway in conditions such as diabetes, cancer, neurodegenerative disease (e.g. Parkinson's Disease), and heart disease (9-12). This review describes the current situation with the use of stem cells in ischaemic stroke, with particular reference to haematopoietic stem cells.

\section{SOURCES OF STEM CELLS FOR STROKE THERAPY}

Although a commonly held belief that 'the brain does not regenerate', it is now accepted that spontaneous post-natal (adult) neurogenesis can occur (13). A number of cell sources for stem cell transplantation are available and these can 
be categorised in several dimensions: exogenous or endogenous sources of cells; embryonic, foetal or adult derivation; neural or non-neural origin; and pluripotential (which can divide indefinitely) or multipotential (which usually regenerate their 'own tissue' but have the ability to transdifferentiate into other tissue cell types).

\section{Neural progenitor cells (NPCs)}

In both human and animal adult brain there are multiple sites of ongoing neuronal and glial formation. Human neural stem cells reside in the periventricular regions and cerebral cortex during development and have been shown to persist into adulthood in a number of sites including the dentate gyrus of the hippocampus, substantia nigra and olfactory bulb (13-17). Animal models demonstrate that ischaemic stroke is associated with differentiation of cells into neurons phenotypically similar to those lost in the ischaemic lesion (18), a finding suggesting that the adult brain has capacity for self repair. As observed in rodents, subventicular and hippocampal cells from adult human brain can be expanded in vitro, differentiate into all three neural cell lineages (neuronal, astrocytic and oligodendroglial) (19) and can improve functional recovery when administered intravenously into a rat model of stroke (20). Conflicting results have been seen with human foetal derived neural stem cells transplanted into stroke rats (21); though the cells were shown to migrate throughout the damaged striatum, cells within the transplant core were undifferentiated and of immature neural lineage. Virtually none of the grafted cells differentiated into astrocytes or oligodendrocytes. However, to date, there is no set of markers that precisely identifies a neural stem cell and distinguishes it from other more limited progenitors, precursors or differentiated cells. The isolation of true neural stem cells and the regions in which they exist remain under investigation. For example, cells cultured from areas outside of the striatal subventricular zone in the post-natal brain demonstrate a more limited capacity for self renewal than well characterised ventricular subependymal neural stem cells (22). The formal identification of cells as neural stem cells still requires functional demonstration of multipotency, self-renewal and longevity. 
Embryonic and foetal stem cells

Sufferers of Parkinson's Disease appear to have benefited from human foetal stem cell transplantation (11), but these cells are in limited supply and their use is fraught with ethical issues in obtaining human tissue for the purpose of obtaining stem cells. Embryonic stem cells are capable of producing large quantities of neural progenitors and, in principle, are pluripotent with unlimited expandability; murine embryonic stem cells have been observed to differentiate into neurons and glial cells when grafted into stroke rats $(23,24)$ and survive for up to 12 weeks. A potential drawback is that they tend to develop a heterogeneous mix of neural precursors and differentiated neurons or glia as well as residual stem cells and a small percentage of non-neural cells (25); the challenge here is to direct differentiation into producing a homogenous cell population. Another disadvantage is their potential for malignant transformation. For example, when undifferentiated murine embryonic stem cells were xenotransplanted into a rat model of stroke, neuronal differentiation was observed; when the same cells were transplanted into the homologous mouse brain, the cells did not migrate and they produced a highly malignant teratocarcinoma (26).

\section{Porcine foetal cells}

Patients with Parkinson's Disease and Huntington's Disease have undergone stem cell transplantation with foetal porcine neurons $(27,28)$ and this donor source is considered as relatively safe. However, the insertion of foreign cells brings the risk of rejection and the need for chronic immunosuppression. Furthermore, xenotransplantation may lead to transmission of porcine viruses, such as the porcine endogenous retrovirus, although one study did not find any evidence of this problem (29).

\section{Immortalised cell lines}

Cells derived by either genetic transformation or cultured embryonic and adult tissue offer a ready and unlimited source of cells, thereby reducing ethical concerns in obtaining aborted foetal tissue. For example, LBS-Neurons (Layton 
Bioscience, Inc) were produced from a NT2/D1 human precursor cell line and induced to differentiate into neurons by the addition of retinoic acid. This cell line was originally derived from a human testicular tumour more than 20 years ago (30) and the final product gives a neuronal cell population virtually indistinguishable from terminally differentiated post-mitotic neurons (31). Malignant transformation following therapeutic transplantation of this cell type is a key concern for this approach.

Stem cells derived from the blood and bone marrow Bone marrow stromal cells, umbilical cord blood and peripheral blood stem cells (PBSCs) are alternative sources of stem cell and their use carries minimal ethical unease when transplanted in an autologous manner. Bone marrow and umbilical cord blood are composed of multiple cell types containing haematopoietic and endothelial precursors (CD34+ cells) and nonhaematopoietic cells (mesenchymal stromal or CD34- cells). Approximately 10$20 \%$ of bone marrow derived stem cells (BMSCs) are multipotent, with the remaining representing more differentiated committed cells (32). It is contentious whether these latter cells can transdifferentiate into neural cells; bone marrow derived cells can adopt neural characteristics (33-35) but the cells are atypical (spherical in nature with few processes (36)) and it is argued that transplanted cells spontaneously fuse with recipient cells and subsequently adopt their phenotype (37). Additionally, murine haematopoietic stem cells demonstrate an age-dependent dimunition of self-renewal, increased apoptosis and functional exhaustion under conditions of stress (38). Nevertheless, bone marrow derived stem cells improved outcome in experimental models of stroke $(39,40)$, and preserved cognitive function has also been seen with intravenous transplantation of mesenchymal stem cells into rat models of Middle Cerebral Artery occlusion (MCAo) (41). Similarly, behavioural and neurological improvement has been demonstrated with intravenous infusion of CD133+ cells in stroke rats (42); the stem cell marker CD133, a transmembrane cell surface antigen, is specifically expressed on 30$75 \%$ of CD34+ cells and has potential benefit for stem cell transplantation since they are less differentiated. However, in this particular study (42), 
behavioural improvement was only apparent using intravenous transplantation within 1 hour of the stroke (compared to delivery at 3 days post stroke) and reduction of cerebral infarct size was only seen when the cells were transplanted intracerebrally.

Haematopoietic stem cells (CD34+ cells)

Haematopoietic stem cells (HSCs) are adult stem cells (the origins of which are poorly understood) that give rise to all blood cell types including myeloid and lymphoid lineages. The CD34 molecule is a cell surface glycoprotein expressed on HSCs and used to facilitate their identification, though CD34-ve HSCs may exist (43). An ischaemic stroke leads to mobilisation of CD34+ cells (as also seen in myocardial infarction (44)), which occurs in bursts over the first 10 days post stroke $(45,46)$; those with higher levels of CD34+ cell mobilisation have a better neurological outcome (45). The origin and fate of these cells are not known. Interestingly, circulating CD34+ counts are inversely related to subsequent recurrent cerebral infarction (47) and cardiovascular events (48). Considering these changes, it is reasonable to hypothesis that promoting the mobilisation of CD34+ cells may be of therapeutic benefit. In one recent study, mononuclear cells were isolated and cultured ex vivo from the peripheral blood of 30 acute stroke patients (49). These 'outgrowth' cells demonstrated a heterogenous population of cells with endothelial and neuronal morphologies; the neuronal outgrowth cells, transplanted 4 days post ischaemia into rat brains, survived (for over 6 months), differentiated into neuronal phenotypes and helped improve functional recovery.

\section{Mobilisation of stem cells}

Production of stem cells derived from the bone marrow are stimulated by hormones called colony stimulating factors (CSFs). Stem cell factor (SCF) regulates differentiation of $\mathrm{CD} 34+$ stem cells; granulocyte-colony stimulating factor (G-CSF) - neutrophils; erythropoietin (EPO) - red blood cells; granulocyte-macrophage-colony stimulating factor (GM-CSF) - macrophages and neutrophils; macrophage-colony stimulating factor (M-CSF or CSF-1) monocytes; and thrombopoietin (TPO) - platelets. SCF, G-CSF, EPO, GM-CSF 
and M-CSF have all been evaluated in pre-clinical models of ischaemic stroke (50-54); studies using G-CSF and EPO have advanced to human stroke trials.

\section{Granulocyte-colony stimulating factor (G-CSF)}

Intentional recruitment of haematopoietic CD34+ stem cells from bone marrow to peripheral blood with G-CSF is a clinical process termed peripheral blood stem cell (PBSC) mobilisation. Although the mechanism involved in this process is largely unknown, G-CSF alone or with chemotherapy is used routinely in clinical practice to reduce the duration of neutropenia in patients with haematological disease, or for mobilising and harvesting PBSCs for subsequent autologous or allogenic infusion. Its use in stroke is novel and under investigation in both animals and humans. For therapeutic purposes, autologous marrow stem cells could be obtained but this is unattractive in view of the need for multiple marrow punctures.

In rat and mice models of ischaemic stroke, a number of groups have demonstrated G-CSF to be neuroprotective at various doses (55), in the presence of thrombolysis $(56,57)$, induce functional recovery $(52,58)$ and promote angiogenesis (58-60) and neurogenesis $(58,60,61)$. All have illustrated that G-CSF causes a reduction in stroke lesion volume. However, GCSF can also lead to impaired behavioural function (62) and may have no benefit when given in the chronic phase of stroke (63) or in global ischaemic models (64).

The mechanisms of action of G-CSF are probably multimodal. Angiogenesis and neurogenesis may occur secondary to CD34+ cell mobilisation but further work on the effects of G-CSF reveal that neurons and adult neural stem cells express a G-CSF receptor and its expression is induced by ischaemia (61). Preclinical studies also show that G-CSF may have an anti-inflammatory role as it causes suppression of iNOS (65) and other inflammatory mediators such as interleukin-1 beta (66). It is thought that the neuroprotective effect of G-CSF is mediated by anti-apoptotic activity via up-regulation of Stat 3 (signal 
transducer and activator of transcription 3) and the JAK/STAT signaling pathway (65).

\section{MECHANISMS OF RECOVERY AFTER STROKE}

Motor, sensory and cognitive dysfunction are common results of stroke and cause considerable disability and social distress. Restoration of movement and motor function forms the focus of rehabilitation based on physical therapy. Recovery of motor and cognitive function occurs to a variable degree through a number of pathways (67-71): unmasking - recruitment of existing but latent connections; sprouting - development of new neural connections (including synaptogenesis); long term potentiation - enhancement of memory and learning; resolution of diaschisis (remote functional depression); and neurogenesis - replacing lost neurones. Additionally, animal models of recovery of function after stroke reveal that repetitive practice or exercise can evoke endogenous neurogenesis and the expression of signalling molecules (perhaps better called 'regenokines') such as brain derived neurotrophic factor (BDNF), which then promotes neuronal repair, enhancing learning and memory (72).

There is increasing interest in the use of interventions that might augment these normal restorative events after stroke, either pharmacologically with drugs such as amphetamine ('rehabilitation pharmacology') (73) or, more recently, through the use of stem cells. Advances in molecular biology are creating opportunities to use cellular therapies to enhance neuronal regeneration in adjunct to a neuro-rehabilitation programme. However, the mechanism by which stem cells may improve recovery is still poorly understood. There are two theories: neuroprotection - preventing damaged neurons undergoing cell death in the acute phase of cerebral ischaemia; and neurorepair - the repair of broken neuronal networks in the chronic phase of cerebral ischaemia. When considering how stem cells promote recovery, there is probably some overlap between these two groups. 
Reduced apoptosis and inflammation

An intervention that reduces stroke lesion size, usually by decreasing cell death within the ischaemic penumbra, indicates neuroprotective activity. This mechanism has been demonstrated with intravenous administration of haematopoietic stem cells and via intracerebral grafting of human neural stem cells in ischaemic stroke models $(74,75)$. However, a reduction in lesion volume is not always seen with transplantation of stem cells from a variety of sources $(39,76-78)$, this perhaps relating to the method and time of administration post stroke.

Neuroprotection could also be secondary to reducing inflammatory responses. It is likely that stem cells play a pivotal role in the regulation of the inflammatory cascade via the production of cytokines and growth factors and it might be expected that a cell transplant would induce or exacerbate inflammation. An exaggerated inflammatory response in the peri-infarct area has been observed in a murine model of stroke treated with G-CSF (62). Conversely, the use of human cord blood cells in a rat model of stroke had the opposite effect by decreasing the inflammatory infiltrate as indicated by a reduction in the expression of pro-inflammatory cytokines (79).

Recruitment of endogenous neural progenitor cells (NPC)

Since progenitor cells exist within the brain, and neurones, glia and vascular cells can be renewed, it might be thought that significant neurogenesis might take place after stroke. Although there are a number of rodent models investigating endogenous neurogenesis in cerebrovascular disease (80-82), few studies have been reported in humans. In one, histological examination was performed in an 84 year old patient who suffered a stroke 1 week prior to death (83). Using a neural stem cell label, large numbers of neural stem cells, vascular endothelial growth factor-immunopositive cells, and new blood vessels around the region of infarction were present suggesting the presence of ischaemia induced NPC recruitment and neovascularisation. Other studies have also shown the presence of ischaemia-induced endogenous neurogenesis (18). 
Growth factors such as BDNF and nerve growth factor (NGF) are involved in the regulation of brain stem cell division and differentiation. Enhancing these naturally occurring neurogenic factors through exogenous administration offers a potential treatment for stroke. However, only one molecule has been tested to date; in a phase II/III trial (286 patients) of basic fibroblast growth factor (bFGF), treatment was ineffective, even showing a trend to hazard, and caused leucocytosis and hypotension (84). The use of treatments targeting a single growth factor pathway in pathophysiological states might have limited effect, as has been seen with numerous neuroprotectants with unimodal mechanisms of action (85). Stem cells offer a potential multimodal mechanism of action, including recruitment of endogenous progenitor cells via secretion of growth factors.

\section{Neurogenesis}

Whether stem cells can improve recovery by replication and differentiation ('direct neurogenesis'), and thereby replace damaged brain cells and reconstruct neural circuitry, remains unclear with limited and conflicting evidence. In rats with induced MCAo, transplanted neurospheres survived 4 weeks post transplant with the majority of migrating cells expressing a neuronal phenotype (including doublecortin, $\beta$-tubulin and glial fibrillary acid protein [GFAP] markers) (76). Neurospheres derived from adult stroke rats can also differentiate into glia (as well as neurons), and can migrate towards the ischaemic lesion (86). A human neural stem cell line (CTX0E03, ReNeuron Group plc (87)), derived from human somatic stem cells following genetic modification with an immortalising gene, can differentiate into neurons and astrocytes, and induce significant improvements in both sensorimotor and gross motor function in the rat MCAO model of stroke 6 to 12 weeks post grafting (88). Finally, in mice incapable of developing cells of the myeloid and lymphoid lineages, transplanted adult bone marrow cells (BMCs) migrated into the brain and differentiated into cells that expressed neuron specific antigens (NeuN, a nuclear protein that is found exclusively in neurons) (34). In contrast, no evidence of neural-like cells was found in another study of mice transplanted with BMCs (89). Other groups have also failed to detect 
differentiation of haematopoietic stem cells into neural tissue (90). In fact, in the positive studies showing cell differentiation into a neural phenotype, only small numbers of cells survived suggesting that integration into host circuitry is not the only or main mechanism of action to enhance functional recovery. Nevertheless, the finding that response may depend on the number of cells administered ('dose response') is compatible with beneficial effects being mediated by cell replacement (91).

\section{Angiogenesis}

Neurogenesis alone will not lead to recovery since neurones need nutritional support from the vasculature and new vessels will need to develop. Angiogenesis has been found experimentally, as shown when bone marrowderived CD34+ cells were administered intravenously to mice 48 hours after stroke induction (74); accelerated neovascularisation occurred in comparison with mice injected with CD34- cells. Furthermore, administration of an antiangiogenic agent prevented the beneficial effect of CD34+ precursors (74). While angiogenesis could reflect differentiation of haematopoietic stem cells into blood vessel wall cells, an indirect effect is also likely since human CD34+ cells have been shown to secrete numerous angiogenic factors, including vascular endothelial growth factor (VEGF) and insulin-like growth factor (IGF1) (92). Hence, a rich vascular environment mediated by CD34+ cells might enhance subsequent neuronal regeneration.

\section{Plasticity}

Neuroplasticity refers to organisational changes in the brain so that individual neurones or networks adapt their function. This theory forms the basis for goal-directed, therapeutic rehabilitation. Stem cells may augment this process via various mechanisms of recovery, including sprouting and unmasking, but the evidence in stroke remains limited. Sprouting has been seen in experimental stroke following intravenous administration of human bone marrow stromal cells to rats; a 50\% reduction in lesion volume was seen in comparison to saline-treated controls (93). In contrast to this, treatment with 
human umbilical cord blood cells did not improve sensorimotor or cognitive outcome in stroke rats (78) in one of the few reported negative studies.

\section{Stem cell migration}

Several experimental paradigms have tested the fate of stem cells when not implanted directly into the site of injury. Under ischaemic conditions, transplanted bone marrow stromal cells selectively migrated to the ischaemic hemisphere of the damaged brain in rats (94) suggesting that the injured brain might specifically attract these cells. In one study, cultured embryonic cells (D3 cell line) were incubated with superparamagnetic iron-oxide nanoparticles (to confer visibility with magnetic resonance imaging [MRI]) and then grafted into the normal hemisphere of rats given transient MCA ischaemia 14 days earlier; contrast was tracked with T2* weighted MRI, which is highly sensitive to iron-label, and was seen to migrate to the ischaemic hemisphere by 3-7 days and remain there for at least 20 days post implantation (95). In another study, G-CSF was given to normal human donors to mobilise peripheral blood stem cells, the CD34+ cells being extracted, separated immunomagnetically and labelled (96). The cells were then grafted into the normal hemisphere of rats given permanent MCAO ischaemia 7 days earlier. Cells were tracked by T2* MRI migrating to the lesion side with label remaining for at least 21-50 days (96). Furthermore, human cells were present in the lesion, corpus callosum and subventricular zone when assessed by immunohistochemistry. Uncertainty remains with the processes behind stem cell migration though some inroads have been made. For example, it appears that stromal cell derived factor-1alpha (SDF-1alpha) and its receptor CXCR4 play an important role in the migration of intravenously transplanted MSCs (97).

\section{CLINICAL TRIALS OF STEM CELL TRANSPLANTATION AFTER STROKE}

There have been no large-scale clinical trials of stem cell transplantation in stroke. However, a number of safety studies have been reported (see table 1 ).

In one non-controlled study, cultured neuronal cells, derived from an immortalised cell-line (LBS-Neurons), were transplanted into 12 patients (age 
44-75) with stroke (primarily involving basal ganglia) (98). Patients received one of 2 doses of cells via CT-guided, stereotactic-targeting of cell implants; immunosuppression was covered with intravenous methylprednisolone (during surgery) and then cyclosporine for 8 weeks. Although functional outcome could not be assessed since the study was too small and had no control group, PET scanning in 6 patients showed increased metabolic activity, suggesting either cell viability or the presence of inflammatory cells (98). Interestingly, detailed histopathological study of the brain from one of the study patients who died at 27 months after cell implantation identified survival of transplanted neuronal cells with no evidence of malignancy (99). The potential for de-differentiation of transplanted cells back to a malignant state is a theoretical concern with the use of transformed stem cells derived from tumours, although pre-clinical studies in mice with this cell line (NT2) have demonstrated no toxicity or tumourgenicity (100).

As a follow up to this study, the same researchers performed a phase two randomised trial, using the same cell line, in 18 patients (101). Patients were between 18 and 75 years and had a fixed motor deficit that was stable for at least 2 months. The treated group $(n=14)$ received one of two doses of implanted cell and a rehabilitation programme; the control group $(n=4)$ had rehabilitation alone. The primary outcome measure, the change in the European Stroke Scale motor score at 6 months, did not differ between the two groups (101).

A safety and feasibility study of the use of foetal porcine cells in patients 1.510 years after a middle cerebral artery infarct (affecting the striatum) has also recently been performed (102). To prevent rejection, cells were pre-treated with anti-MHC1 antibody and no immunosuppressive drugs were given to the patients. Of the 12 planned patients, only 5 patients entered the study following which the US Federal Drug Administration halted the trial prematurely after 2 patients developed serious adverse events. One patient suffered a cortical vein occlusion secondary to the surgical procedure, and the other experienced generalised and partial seizures while hyperglycaemic. 
These observations highlight the potential risks with intracranial transplantation of stem cells and suggest that other modes of delivery of stem cells should be considered.

One such alternative is to use autologous stem cells. A recent randomised controlled trial tested mysenchymal stem cells (MSCs) in patients with middle cerebral artery territory infarction (103). 5 patients with persistent neurological deficit 7 days after their ischaemic stroke were allocated to receive intravenous MSCs and 25 patients acted as controls (no additional intervention and no sham procedure). MSCs were acquired from bone marrow aspirates and then cultured ex vivo to obtain sufficient quantities before reinjection into the patient 4-6 and then 7-9 weeks after symptom onset. At 1 year, 10 patients in the control group were lost to follow-up but no serious adverse events such as infection or tumour formation had occurred. The study has demonstrated feasibility in administering ex-vivo cultured MSCs but the authors have been heavily criticised for both its methods and conclusions reached (104) and have since issued an apology for having plagiarised sections of their discussion (105).

\section{G-CSF in clinical stroke}

Three small, randomised controlled trials have assessed the safety of recombinant G-CSF after ischaemic stroke (table 2 ). A recently completed phase IIa dose-escalation trial assessed G-CSF in 36 patients (G-CSF, n=24; placebo, $n=12$ ) with sub-acute ischaemic stroke (106). Patients were treated between 7-30 days post ictus with increasing doses of G-CSF $(1-10 \mu \mathrm{g} / \mathrm{kg}$ given either once or daily for 5 days) given subcutaneously. G-CSF increased circulating CD34+ counts 10-fold (as measured by flow cytometry) in a dosedependent manner and with the peak level occurring at day 5. A dosedependent increase in white cell count at day 3 and decrease in platelet count also occurred, expected effects of G-CSF. Serious adverse event rates did not differ although the frequency of infection was non-significantly higher in G-CSF treated patients ( $29 \%$ vs. $25 \%$ ); stroke recurrence rates did not differ between the treatment groups. 
In a second trial, 10 patients with a National Institutes of Health Stroke Scale (NIHSS) score between 9 and 20 and within 7 days of stroke onset were randomised to 5 days of G-CSF ( $15 \mu \mathrm{g} / \mathrm{kg}$ per day, $\mathrm{n}=7$ ) or control (routine care, $n=3$ ) (107). Over a 12-month follow-up, patients who received G-CSF had a significantly greater improvement in neurological function and disability than control patients. There was no aggravation of stroke symptoms and no thrombotic complications. Unfortunately, the results are confounded since many patients receiving G-CSF had a lacunar infarction, a type of stroke that often improves spontaneously. In the third trial, 15 patients were randomized within 1 week of stroke onset to receive G-CSF and 30 to placebo (108). A non-significant reduction in NIHSS was noted at day 10 , which became significant at day 20 .

In a Cochrane systematic review of the three trials of G-CSF (as well as other colony stimulating factors) for stroke, G-CSF did not significantly alter functional outcome although there was a trend to reduced impairment (109). Furthermore, G-CSF was well tolerated and appeared to be safe, and significantly increased white cell count (109). The long term safety of G-CSF has been monitored in 101 normal donors who had G-CSF for the purpose of mobilising PBSCs prior to allogenic transplantation; there were no obvious adverse effects over a 3-6 year follow-up period and, in particular, the rates of cancer and vascular disease were not increased (110). Nevertheless, G-CSF may cause a hypercoagulable state (111), a potential mechanism for increasing recurrent stroke rates. In healthy donors receiving G-CSF, in vitro bleeding time is decreased with increased levels of Factor VIII and fibrinogen, and reduced protein $\mathrm{C}$ and $\mathrm{S}$ activity (111).

Further trials of G-CSF are underway including a dose-escalation (30$180 \mu \mathrm{g} / \mathrm{kg})$ study in acute ischaemic stroke $(\mathrm{n}=44)$, a trial in sub-acute stroke $(n=60)$, and a trial in 40 patients with chronic stroke ( 3 months from ictus); a non-controlled study is also ongoing (109). Data from these completed and ongoing trials will inform whether larger phase III trials of G-CSF are 
warranted. Although other colony stimulating factors such as stem cell factor (SCF), granulocyte-macrophage-colony stimulating factor (GM-CSF) and macrophage-colony stimulating factor (M-CSF or CSF-1) also mobilise bone marrow-derived stem cells (and recombinant forms are available), trials in patients with stroke have not been reported (109).

\section{FUTURE DEVELOPMENT OF STEM CELLS FOR THE TREATMENT OF STROKE}

Although many studies assessing stem cells in pre-clinical stroke have been reported, and limited clinical trial data are now available, many questions remain unanswered. There is also a noticeable lack of published studies reporting a negative or neutral outcome. This publication bias can perpetuate the development of inappropriate clinical trials that will not answer the uncertainties that remain in this field (112). It is vital that future experimental studies are of high quality (for example, conforming to the STAIR criteria (113)) and have standardised protocols and outcome measures so they can be fairly compared.

One possible advantage of treating stroke with stem cells is a potentially wide therapeutic window. The optimal time of administration post stroke will relate to the micro-environment of the damaged area, i.e. should stem cells be administered during the acute phase of stroke at a time when inflammatory responses are maximal or will delayed treatment be effective at a time when scar tissue has formed? The inflammatory response can last up to several weeks and it may be that stem cells could exacerbate or attenuate this process. Relatively few studies have analysed the effects of stem cells in intracerebral haemorrhage (ICH) but a reduction in inflammation was observed in one study assessing intravenous human neural stem cells in experimental ICH (114); the majority of the transplanted cells were detected in the marginal zones of the spleen with only very few seen in the brain sections. Adipose derived stem cells (ASCs) have also been transplanted into experimental ICH (115), and again, a reduction in the inflammatory response was seen but ASCs did not reveal any evidence of neuronal transdifferentiation. 
The ideal route of stem cell delivery is also unclear. This has been addressed in one pre-clinical study comparing intra-striatal, intra-ventricular and intravenous administration of neural precursor cells with all routes resulting in cells targeting the lesion (116). In contrast to this, another study assessing intravenous administration of human umbilical cord cells in stroke rats did not detect any evidence of stem cells in the target lesion (117). If intracerebral administration is the most effective (though probably the most hazardous) then should cells be transplanted directly into the ischaemic lesion or distant to it (reducing the chance of damaging vital structures) and relying on spontaneous stem cell migration $(76,95,118)$ ? Existing human safety trials used intracerebral injections of stem cells directly into the peri-infarct area $(98,101)$, a decision appearing not to be based on any substantial pre-clinical work. The role of immunosupression in such exogenous transplants also remains elusive.

There are multiple sources of exogenous stem cells available (at least 5 types of adult stem cells are in commercial development (119)) and the cell type that should be transplanted for a given stroke type and size is undetermined. Endogenous stem cell treatment is an attractive alternative, removing the need for immunosuppression. CD34+ stem cells can be mobilised into peripheral blood with G-CSF in ischaemic stroke patients in a dose dependent manner (106), but it may be the direct neuroprotective qualities of G-CSF that play a more important role. G-CSF already possesses a good safety record and pharmacological profile for use in humans and, though it is essential that thorough pre-clinical work precede human clinical trials (pre-clinical data on ideal doses and times of administration of G-CSF are still outstanding), the use of G-CSF and other colony stimulating factors such as erythropoietin have progressed to phase II and III stroke trials.

\section{CONCLUSION}

There is much hope and hype attached to the development of stem cell therapies. However, many questions remain to be answered and patients 
should not, at present, undergo stem cell therapy out with a properly designed randomised controlled trial.

\section{ACKNOWLEDGEMENTS}

TE is funded by the MRC; PM and PB are recipient of a grant on HSCs from ESRC; PB is a Stroke Association Professor of Stroke Medicine. TE and PB are running an MRC funded phase II trial assessing GCSF mobilisation of HSCs in ischaemic stroke.

\section{REFERENCES}

1. Rothwell PM, Coull AJ, Silver LE, et al. Population-based study of event-rate, incidence, case fatality, and mortality for all acute vascular events in all arterial territories (Oxford Vascular Study). Lancet 2005;366(9499):1773-83.

2. Bath PM, Lees KR. ABC of arterial and venous disease. Acute stroke. BMJ 2000;320(7239):920-3.

3. Bath PM, Lindenstrom E, Boysen G, et al. Tinzaparin in acute ischaemic stroke (TAIST): a randomised aspirin-controlled trial. Lancet 2001;358(9283):702-10.

4. Ferro JM, Davalos A. Other neuroprotective therapies on trial in acute stroke. Cerebrovascular Diseases 2006;2:127-30.

5. The ATLANTIS ECASS and NINDS rt-PA Study Group Investigators. Association of outcome with early stroke treatment: pooled analysis of ATLANTIS, ECASS, and NINDS rt-PA stroke trials. The Lancet 2004;363:768-813.

6. Vahedi K, Hofmeijer J, Juettler E, et al. Early decompressive surgery in malignant infarction of the middle cerebral artery: a pooled analysis of three randomised controlled trials. [see comment]. Lancet Neurology 2007;6(3):215-22.

7. Stroke Unit Trialists C. Organised inpatient (stroke unit) care for stroke. Cochrane Database of Systematic Reviews. 2007((4):CD000197).

8. Melton DA, Cowan C. "Stemness": Definitions, Criteria and Standards. In: Lanza R, editor. Handbook of Stem Cells. 1st ed. Burlington, San Diego, USA: Elsevier Academic Press; 2004. p. xxv - xxxi.

9. Burt R. Safety and efficacy study of autologous stem cell transplantation for early onset Type I Diabetes Mellitus. http://clinicaltrials.gov/ct/show/NCT00315133. Ongoing.

10. NCI. Donor stem cell transplant in treating patients with hematological cancer. http://clinicaltrials.gov/ct/show/NCT00054327. Ongoing.

11. Freed CR, Greene PE, Breeze RE, et al. Transplantation of embryonic dopamine neurons for severe Parkinson's disease. New England Journal of Medicine 2001;344(10):710-9.

12. Stamm C, Kleine HD, Choi YH, et al. Intramyocardial delivery of CD133+ bone marrow cells and coronary artery bypass grafting for chronic ischemic heart disease: safety and efficacy studies. Journal of Thoracic \& Cardiovascular Surgery 2007;133(3):717-25.

13. Eriksson PS, Perfilieva E, Bjork-Eriksson T, et al. Neurogenesis in the adult human hippocampus. Nature Medicine 1998;4(11):1313-7.

14. Roy NS, Wang S, Jiang L, et al. In vitro neurogenesis by progenitor cells isolated from the adult human hippocampus. Nature Medicine 2000;6(3):271-7.

15. Richardson RM, Holloway KL, Bullock MR, Broaddus WC, Fillmore HL. Isolation of neuronal progenitor cells from the adult human neocortex. Acta Neurochirurgica 2006;148(7):773-7. 
16. Zhao M, Momma S, Delfani K, et al. Evidence for neurogenesis in the adult mammalian substantia nigra. Proceedings of the National Academy of Sciences of the United States of America 2003;100(13):7925-30.

17. Pagano SF, Impagnatiello F, Girelli M, et al. Isolation and characterization of neural stem cells from the adult human olfactory bulb. Stem Cells 2000;18(4):295-300.

18. Arvidsson A, Collin T, Kirik D, Kokaia Z, Lindvall O. Neuronal replacement from endogenous precursors in the adult brain after stroke. Nature Medicine 2002;8(9):963-70.

19. Kukekov VG, Laywell ED, Suslov O, et al. Multipotent stem/progenitor cells with similar properties arise from two neurogenic regions of adult human brain. Experimental Neurology 1999;156(2):333-44.

20. Chu K, Kim M, Park KI, et al. Human neural stem cells improve sensorimotor deficits in the adult rat brain with experimental focal ischemia. Brain Research 2004;1016(2):145-53.

21. Darsalia V, Kallur T, Kokaia Z. Survival, migration and neuronal differentiation of human fetal striatal and cortical neural stem cells grafted in stroke-damaged rat striatum. European Journal of Neuroscience 2007;26(3):605-14.

22. Seaberg RM, Smukler SR, van der Kooy D. Intrinsic differences distinguish transiently neurogenic progenitors from neural stem cells in the early postnatal brain. Developmental Biology 2005;278(1):71-85.

23. Buhnemann C, Scholz A, Bernreuther C, et al. Neuronal differentiation of transplanted embryonic stem cell-derived precursors in stroke lesions of adult rats. Brain 2006;129(Pt 12):3238-48.

24. Wei L, Cui L, Snider BJ, et al. Transplantation of embryonic stem cells overexpressing Bcl2 promotes functional recovery after transient cerebral ischemia. Neurobiology of Disease 2005;19(1-2):183-93.

25. Pollard S, Conti L, Smith A. Exploitation of adherent neural stem cells in basic and applied neurobiology. Regenerative Medicine 2006;1(1):111-118.

26. Erdo F, Buhrle C, Blunk J, et al. Host-dependent tumorigenesis of embryonic stem cell transplantation in experimental stroke. Journal of Cerebral Blood Flow \& Metabolism 2003;23(7):780-5.

27. Schumacher JM, Ellias SA, Palmer EP, et al. Transplantation of embryonic porcine mesencephalic tissue in patients with PD. Neurology 2000;54(5):1042-50.

28. Dunnett SB, Rosser AE. Stem cell transplantation for Huntington's disease. Experimental Neurology 2007;203(2):279-92.

29. Dinsmore JH, Manhart C, Raineri R, Jacoby DB, Moore A. No evidence for infection of human cells with porcine endogenous retrovirus (PERV) after exposure to porcine fetal neuronal cells. Transplantation 2000;70(9):1382-9.

30. Andrews PW, Damjanov I, Simon D, et al. Pluripotent embryonal carcinoma clones derived from the human teratocarcinoma cell line Tera-2. Differentiation in vivo and in vitro. Laboratory Investigation 1984;50(2):147-62.

31. Trojanowski JQ, Kleppner SR, Hartley RS, et al. Transfectable and transplantable postmitotic human neurons: a potential "platform" for gene therapy of nervous system diseases. Experimental Neurology 1997;144(1):92-7.

32. Bianco P, Robey G. Skeletal stem cells. In: Lanza R, editor. Handbook of stem cells. 1st ed. Burlington, San Diego, USA: Elsevier Academic Press; 2004. p. 415-4125.

33. Sanchez-Ramos J, Song S, Cardozo-Pelaez F, et al. Adult bone marrow stromal cells differentiate into neural cells in vitro. Experimental Neurology 2000;164(2):247-56.

34. Mezey E, Chandross KJ, Harta G, Maki RA, McKercher SR. Turning blood into brain: cells bearing neuronal antigens generated in vivo from bone marrow. Science 2000;290(5497):1779-82.

35. Li Y, Chen J, Chopp M. Adult bone marrow transplantation after stroke in adult rats. Cell Transplantation 2001;10(1):31-40. 
36. Zhao LR, Duan WM, Reyes M, Keene CD, Verfaillie CM, Low WC. Human bone marrow stem cells exhibit neural phenotypes and ameliorate neurological deficits after grafting into the ischemic brain of rats. Experimental Neurology 2002;174(1):11-20.

37. Terada N, Hamazaki T, Oka M, et al. Bone marrow cells adopt the phenotype of other cells by spontaneous cell fusion. Nature 2002;416(6880):542-5.

38. Rossi DJ, Bryder D, Seita J, Nussenzweig A, Hoeijmakers J, Weissman IL. Deficiencies in DNA damage repair limit the function of haematopoietic stem cells with age. Nature 2007;447(7145):725-9.

39. Chen J, Sanberg PR, Li Y, et al. Intravenous administration of human umbilical cord blood reduces behavioral deficits after stroke in rats. Stroke 2001;32(11):2682-8.

40. Nagai A, Kim WK, Lee HJ, et al. Multilineage potential of stable human mesenchymal stem cell line derived from fetal marrow. PLoS ONE [Electronic Resource] 2007;2(12):e1272.

41. Sokolova I, Fedotova O, Zin'Kova N, Kruglyakov P, Polyntsev D. Effect of Mesenchymal Stem Cell Transplantation on Cognitive Function in Rats with Ischaemic Stroke. Cell Technologies in Biology and Medicine 2006;2(4):511-514.

42. Borlongan CV, Evans A, Yu G, Hess DC. Limitations of intravenous human bone marrow CD133+ cell grafts in stroke rats. Brain Research 2005;1048(1-2):116-22.

43. Guo Y, Lubbert M, Engelhardt M. CD34- hematopoietic stem cells: current concepts and controversies. Stem Cells 2003;21(1):15-20.

44. Shintani S, Murohara T, Ikeda H, et al. Mobilization of endothelial progenitor cells in patients with acute myocardial infarction. Circulation 2001;103(23):2776-9.

45. Dunac A, Frelin C, Popolo-Blondeau M, Chatel M, Mahagne M, P P. Neurological and functional recovery in human stroke are associated with peripheral blood CD34+ cell mobilization. J Neurol 2007;254:327-332.

46. Hennemann B, Ickenstein G, Sauerbruch S, et al. Mobilization of CD34+ hematopoietic cells, colony-forming cells and long-term culture-initiating cells into the peripheral blood of patients with an acute cerebral ischemic insult. Cytotherapy 2008;10(3):303-11.

47. Taguchi A, Matsuyama T, Moriwaki H, et al. Circulating CD34-positive cells provide an index of cerebrovascular function. Circulation 2004;109(24):2972-5.

48. Schmidt-Lucke C, Rossig L, Fichtlscherer S, et al. Reduced number of circulating endothelial progenitor cells predicts future cardiovascular events: proof of concept for the clinical importance of endogenous vascular repair. Circulation 2005;111(22):2981-7.

49. Jung KH, Chu K, Lee ST, et al. Identification of neuronal outgrowth cells from peripheral blood of stroke patients. Annals of Neurology 2008;63(3):312-22.

50. Jin K, Mao XO, Sun Y, Xie L, Greenberg DA. Stem cell factor stimulates neurogenesis in vitro and in vivo. Journal of Clinical Investigation 2002;110(3):311-9.

51. Brines ML, Ghezzi P, Keenan S, et al. Erythropoietin crosses the blood-brain barrier to protect against experimental brain injury. Proceedings of the National Academy of Sciences of the United States of America 2000;97(19):10526-31.

52. Gibson CL, Bath PM, Murphy SP. G-CSF reduces infarct volume and improves functional outcome after transient focal cerebral ischemia in mice. Journal of Cerebral Blood Flow \& Metabolism 2005;25(4):431-9.

53. Schabitz WR, Kruger C, Pitzer C, et al. A neuroprotective function for the hematopoietic protein granulocyte-macrophage colony stimulating factor (GM-CSF). Journal of Cerebral Blood Flow \& Metabolism 2008;28(1):29-43.

54. Vincent VA, Robinson CC, Simsek D, Murphy GM. Macrophage colony stimulating factor prevents NMDA-induced neuronal death in hippocampal organotypic cultures. Journal of Neurochemistry 2002;82(6):1388-97.

55. Schabitz WR, Kollmar R, Schwaninger M, et al. Neuroprotective effect of granulocyte colony-stimulating factor after focal cerebral ischemia. Stroke 2003;34(3):745-51. 
56. Kollmar R, Henninger N, Urbanek C, Schabitz W, Schneider A, Schwab S. Effects of GCSF in combination with rt-PA after experimental thromboembolic stroke. Akt Neurol 2004;31.

57. Kollmar R, Henninger N, Urbanek C, Schwab S. G-CSF and rt-PA for the treatment of Experimental Embolic Stroke. Cerebrovascular Diseases 2007;23(Suppl 2):23.

58. Shyu WC, Lin SZ, Yang HI, et al. Functional recovery of stroke rats induced by granulocyte colony-stimulating factor-stimulated stem cells. Circulation 2004;110(13):1847-54.

59. Lee ST, Chu K, Jung KH, et al. Granulocyte colony-stimulating factor enhances angiogenesis after focal cerebral ischemia. Brain Research 2005;1058:120-128.

60. Sehara Y, Hayashi T, Deguchi K, et al. Potentiation of neurogenesis and angiogenesis by GCSF after focal cerebral ischemia in rats. Brain Research 2007;1151:142-9.

61. Schneider A, Kruger C, Steigleder T, et al. The hematopoietic factor G-CSF is a neuronal ligand that counteracts programmed cell death and drives neurogenesis. Journal of Clinical Investigation 2005;115(8):2083-98.

62. Taguchi A, Wen Z, Myojin K, et al. Granulocyte colony-stimulating factor has a negative effect on stroke outcome in a murine modelwa. European Journal of Neuroscience 2007;26(1):126-33.

63. Zhao LR, Berra HH, Duan WM, et al. Beneficial effects of hematopoietic growth factor therapy in chronic ischemic stroke in rats. Stroke 2007;38(10):2804-11.

64. Matchett GA, Calinisan JB, Matchett GC, Martin RD, Zhang JH. The effect of granulocytecolony stimulating factor in global cerebral ischemia in rats. Brain Research 2007;1136(1):200-7.

65. Komine-Kobayashi M, Zhang N, Liu M, et al. Neuroprotective effect of recombinant human granulocyte colony-stimulating factor in transient focal ischemia of mice. Journal of Cerebral Blood Flow \& Metabolism 2006;26(3):402-13.

66. Gibson CL, Jones NC, Prior MJ, Bath PM, Murphy SP. G-CSF suppresses edema formation and reduces interleukin-1 beta expression after cerebral ischemia in mice. Journal of Neuropathology \& Experimental Neurology 2005;64(9):763-9.

67. Jacobs KM, Donoghue JP. Reshaping the cortical motor map by unmasking latent intracortical connections. Science 1991;251(4996):944-7.

68. Carmichael ST, Chesselet MF. Synchronous neuronal activity is a signal for axonal sprouting after cortical lesions in the adult. Journal of Neuroscience 2002;22(14):6062-70.

69. Bliss TV, Collingridge GL. A synaptic model of memory: long-term potentiation in the hippocampus. Nature 1993;361(6407):31-9.

70. Pantano P, Baron JC, Samson Y, Bousser MG, Derouesne C, Comar D. Crossed cerebellar diaschisis. Further studies. Brain 1986;109(Pt 4):677-94.

71. Jin K, Minami M, Lan JQ, et al. Neurogenesis in dentate subgranular zone and rostral subventricular zone after focal cerebral ischemia in the rat. Proceedings of the National Academy of Sciences of the United States of America 2001;98(8):4710-5.

72. Vaynman S, Gomez-Pinilla F. License to run: exercise impacts functional plasticity in the intact and injured central nervous system by using neurotrophins. Neurorehabilitation \& Neural Repair 2005;19(4):283-95.

73. Sprigg N, Bath P. Pharmacological enhancement of recovery from stroke. Current Medical Literature Stroke Review 2005;8(2):33-39.

74. Taguchi A, Soma T, Tanaka H, et al. Administration of CD34+ cells after stroke enhances neurogenesis via angiogenesis in a mouse model. Journal of Clinical Investigation 2004;114(3):330-8.

75. Ishibashi S, Sakaguchi M, Kuroiwa T, et al. Human neural stem/progenitor cells, expanded in long-term neurosphere culture, promote functional recovery after focal ischemia in Mongolian gerbils. Journal of Neuroscience Research 2004;78(2):215-23. 
76. Kelly S, Bliss TM, Shah AK, et al. Transplanted human fetal neural stem cells survive, migrate, and differentiate in ischemic rat cerebral cortex. Proceedings of the National Academy of Sciences of the United States of America 2004;101(32):11839-44.

77. Nystedt J, Makinen S, Laine J, Jolkkonen J. Human cord blood CD34+ cells and behavioral recovery following focal cerebral ischemia in rats. Acta Neurobiologiae Experimentalis 2006;66(4):293-300.

78. Makinen S, Kekarainen T, Nystedt J, et al. Human umbilical cord blood cells do not improve sensorimotor or cognitive outcome following transient middle cerebral artery occlusion in rats. Brain Research 2006;1123(1):207-15.

79. Vendrame M, Gemma C, de Mesquita D, et al. Anti-inflammatory effects of human cord blood cells in a rat model of stroke. Stem Cells \& Development 2005;14(5):595-604.

80. Lee SH, Kim YJ, Lee KM, Ryu S, Yoon BW. Ischemic preconditioning enhances neurogenesis in the subventricular zone. Neuroscience 2007;146(3):1020-31.

81. Ray J, Gage FH. Differential properties of adult rat and mouse brain-derived neural stem/progenitor cells. Molecular \& Cellular Neurosciences 2006;31(3):560-73.

82. Yagita Y, Kitagawa K, Ohtsuki T, et al. Neurogenesis by progenitor cells in the ischemic adult rat hippocampus. Stroke 2001;32(8):1890-6.

83. Minger S, Ekonomou A, Carta E, Chinoy A, Perry R, Ballard C. Endogenous neurogenesis in the human brain following cerebral infarction. Regenerative Medicine 2007;2(1):69-74.

84. Bogousslavsky J, Victor S, Salinas E, et al. Fiblast (Trafermin) in acute stroke: results of the European-Australian phase II/III safety and efficacy trial. Cerebrovascular Diseases 2002;14:239-251.

85. Lees KR, Muir KW. Excitatory amino acid antagonists for acute stroke (Cochrane Review). In: The Cochrane Library. In press ed. Oxford: Update Software; 2002.

86. Zhang R, Zhang Z, Wang L, et al. Activated neural stem cells contribute to stroke-induced neurogenesis and neuroblast migration toward the infarct boundary in adult rats. Journal of Cerebral Blood Flow \& Metabolism 2004;24(4):441-8.

87. Sinden JD. ReNeuron Group plc. Regenerative Medicine 2006;1(1):143-147.

88. Pollock K, Stroemer P, Patel S, et al. A conditionally immortal clonal stem cell line from human cortical neuroepithelium for the treatment of ischemic stroke. Experimental Neurology 2006;199(1):143-55.

89. Castro RF, Jackson KA, Goodell MA, Robertson CS, Liu H, Shine HD. Failure of bone marrow cells to transdifferentiate into neural cells in vivo. Science 2002;297(5585):1299.

90. Wagers AJ, Sherwood RI, Christensen JL, Weissman IL. Little evidence for developmental plasticity of adult hematopoietic stem cells.[see comment]. Science 2002;297(5590):2256-9.

91. Vendrame M, Cassady J, Newcomb J, et al. Infusion of human umbilical cord blood cells in a rat model of stroke dose-dependently rescues behavioral deficits and reduces infarct volume. Stroke 2004;35(10):2390-5.

92. Majka M, Janowska-Wieczorek A, Ratajczak J, et al. Numerous growth factors, cytokines, and chemokines are secreted by human CD34(+) cells, myeloblasts, erythroblasts, and megakaryoblasts and regulate normal hematopoiesis in an autocrine/paracrine manner. Blood 2001;97(10):3075-85.

93. Xiao J, Nan Z, Motooka Y, Low WC. Transplantation of a novel cell line population of umbilical cord blood stem cells ameliorates neurological deficits associated with ischemic brain injury. Stem Cells \& Development 2005;14(6):722-33.

94. Chen J, Li Y, Wang L, et al. Therapeutic benefit of intravenous administration of bone marrow stromal cells after cerebral ischemia in rats. Stroke 2001;32(4):1005-11.

95. Hoehn M, Kustermann E, Blunk J, et al. Monitoring of implanted stem cell migration in vivo: a highly resolved in vivo magnetic resonance imaging investigation of experimental stroke in rat. Proceedings of the National Academy of Sciences of the United States of America 2002;99(25):16267-72. 
96. Jendelova P, Herynek V, Urdzikova L, et al. Magnetic resonance tracking of human CD34 progenitor cells separated by means of immunomagnetic selection and transplanted into injured rat brain. Cell Transplantation 2005;14:173-182.

97. Wang Y, Deng Y, Zhou GQ. SDF-1alpha/CXCR4-mediated migration of systemically transplanted bone marrow stromal cells towards ischemic brain lesion in a rat model. Brain Research 2008;1195:104-12.

98. Kondziolka D, Wechsler L, Goldstein S, et al. Transplantation of cultured human neuronal cells for patients with stroke. Neurology 2000;55(4):565-9.

99. Nelson PT, Kondziolka D, Wechsler L, et al. Clonal human (hNT) neuron grafts for stroke therapy: neuropathology in a patient 27 months after implantation. American Journal of Pathology 2002;160(4):1201-6.

100. Kleppner SR, Robinson KA, Trojanowski JQ, Lee VM. Transplanted human neurons derived from a teratocarcinoma cell line (NTera-2) mature, integrate, and survive for over 1 year in the nude mouse brain. Journal of Comparative Neurology 1995;357(4):618-32.

101. Kondziolka D, Steinberg GK, Wechsler L, et al. Neurotransplantation for patients with subcortical motor stroke: a phase 2 randomized trial. Journal of Neurosurgery 2005;103(1):38-45.

102. Savitz SI, Dinsmore J, Wu J, Henderson GV, Stieg P, Caplan LR. Neurotransplantation of fetal porcine cells in patients with basal ganglia infarcts: a preliminary safety and feasibility study. Cerebrovascular Diseases 2005;20(2):101-7.

103. Bang OY, Lee JS, Lee PH, Lee G. Autologous mesenchymal stem cell transplantation in stroke patients. Annals of Neurology 2005;57(6):874-82.

104. De Keyser J. Autologous mesenchymal stem cell transplantation in stroke patients.[comment]. Annals of Neurology 2005;58(4):653-4; author reply 654-5.

105. Bang OY. An apology: inadvertent error in our article published in June 2005 issue of the Annals of Neurology (Ann Neurol 2005;57:874-882). Annals of Neurology 2005;58(4):659.

106. Sprigg N, Bath PM, Zhao L, et al. Granulocyte-colony-stimulating factor mobilizes bone marrow stem cells in patients with subacute ischemic stroke: the Stem cell Trial of recovery EnhanceMent after Stroke (STEMS) pilot randomized, controlled trial (ISRCTN 16784092). Stroke 2006;37(12):2979-83.

107. Shyu WC, Lin SZ, Lee CC, Liu DD, Li H. Granulocyte colony-stimulating factor for acute ischemic stroke: a randomized controlled trial. CMAJ Canadian Medical Association Journal 2006;174(7):927-33.

108. Zhang JJ, Deng M, Zhang Y, Sui W, Wang L, Sun A. A Short-Term Assessment of Recombinant Granulocyte-Stimulating factor (RHG-CSF) in Treatment of Acute Cerebral Infarction. Cerebrovascular Diseases 2006;21(Suppl 4):143.

109. Bath PM, Sprigg N. Colony stimulating factors (including erythropoietin, granulocyte colony stimulating factor and analogues) for stroke. Cochrane Database of Systematic Reviews 2006;3:CD005207.

110. Cavallaro AM, Lilleby K, Majolino I, et al. Three to six year follow-up of normal donors who received recombinant human granulocyte colony-stimulating factor. Bone Marrow Transplantation 2000;25(1):85-9.

111. Sohngen D, Wienen S, Siebler M, et al. Analysis of rhG-CSF-effects on platelets by in vitro bleeding test and transcranial Doppler ultrasound examination. Bone Marrow Transplant 1998;22:1087-1090.

112. Ioannidis JP. Contradicted and initially stronger effects in highly cited clinical research. JAMA 2005;294(2):218-28.

113. Anonymous. Recommendations for standards regarding preclinical neuroprotective and restorative drug development. Stroke 1999;30(12):2752-8.

114. Lee ST, Chu K, Jung KH, et al. Anti-inflammatory mechanism of intravascular neural stem cell transplantation in haemorrhagic stroke. Brain 2008;131(Pt 3):616-29. 
115. Kim JM, Lee ST, Chu K, et al. Systemic transplantation of human adipose stem cells attenuated cerebral inflammation and degeneration in a hemorrhagic stroke model. Brain Research 2007;1183:43-50.

116. Jin K, Sun Y, Xie L, et al. Comparison of ischemia-directed migration of neural precursor cells after intrastriatal, intraventricular, or intravenous transplantation in the rat. Neurobiology of Disease 2005;18(2):366-74.

117. Borlongan CV, Hadman M, Sanberg CD, Sanberg PR. Central nervous system entry of peripherally injected umbilical cord blood cells is not required for neuroprotection in stroke. Stroke 2004;35(10):2385-9.

118. Modo M, Mellodew K, Cash D, et al. Mapping transplanted stem cell migration after a stroke: a serial, in vivo magnetic resonance imaging study. Neuroimage 2004;21(1):311-7.

119. Martin PA, Coveney C, Kraft A, Brown N, Bath P. Commercial Development of Stem Cell Technology: Lessons from the Past, Strategies for the Future. Regenerative Medicine 2006;1(6):801-807. 
Table 1. Summary of observational and randomised controlled trials involving stem cells after stroke

\begin{tabular}{|c|c|c|c|c|c|c|}
\hline $\begin{array}{l}\text { Author, } \\
\text { year }\end{array}$ & Cells & $\begin{array}{l}\text { Patients } \\
\text { (active / } \\
\text { control) }\end{array}$ & Stroke type & Administration & Immunosuppression & Comments \\
\hline $\begin{array}{l}\text { Kondziolka } \\
2000(98)\end{array}$ & $\begin{array}{l}\text { Immortalised } \\
\text { neuronal }\end{array}$ & $12 / 0$ & $\begin{array}{l}\text { Basal ganglia } \\
\text { infarct }\end{array}$ & $\begin{array}{c}\text { Stereotactic } \\
\text { transplantation } \\
\text { into region of the } \\
\text { stroke }\end{array}$ & $\begin{array}{l}\text { Methylprednisolone } \\
\text { during surgery. } \\
\text { Cyclosporine } 1 \text { week } \\
\text { prior to surgery and } \\
\text { continued for } 8 \text { weeks }\end{array}$ & $\begin{array}{c}\text { No effect on functional } \\
\text { outcome. PET showed } \\
\text { increased metabolic } \\
\text { activity. }\end{array}$ \\
\hline $\begin{array}{l}\text { Kondziolka } \\
2005(101)\end{array}$ & $\begin{array}{l}\text { Immortalised } \\
\text { neuronal }\end{array}$ & $14 / 4$ & $\begin{array}{l}\text { Basal ganglia } \\
\text { infarct }\end{array}$ & $\begin{array}{c}\text { Stereotactic } \\
\text { transplantation } \\
\text { into region of the } \\
\text { stroke }\end{array}$ & $\begin{array}{l}\text { Methylprednisolone } \\
\text { during surgery. } \\
\text { Cyclosporine } 1 \text { week } \\
\text { prior to surgery and } \\
\text { continued for } 6 \text { months }\end{array}$ & $\begin{array}{c}\text { No effect on functional } \\
\text { outcome. }\end{array}$ \\
\hline $\begin{array}{c}\text { Savitz } \\
2005(102)\end{array}$ & Foetal porcine & $\begin{array}{l}5 \text { (of planned } \\
12) / 0\end{array}$ & MCA infarct & $\begin{array}{c}\text { Stereotactic } \\
\text { transplantation } \\
\text { into region of the } \\
\text { stroke }\end{array}$ & $\begin{array}{l}\text { None (cells pre-treated } \\
\text { with anti-MHC antibody) }\end{array}$ & $\begin{array}{l}\text { Study stopped early } \\
\text { after } 2 \text { SAEs }\end{array}$ \\
\hline $\begin{array}{l}\text { Bang } 2005 \\
\quad(103)\end{array}$ & $\begin{array}{l}\text { Autologous, } \\
\text { mysenchymal }\end{array}$ & $5 / 25$ & MCA infarct & Intravenous & None & $\begin{array}{l}\text { Questionable study } \\
\text { quality, e.g. } 10 \\
\text { patients lost to follow- } \\
\text { up }\end{array}$ \\
\hline
\end{tabular}

MCA Middle Cerebral Artery; SAE Serious Adverse Event; BI Barthel Index 
Table 2. Summary of human clinical trials in G-CSF and ischaemic stroke

\begin{tabular}{|c|c|c|c|c|c|}
\hline Author / year & Trial Design & G-CSF Regimen & $\begin{array}{l}\text { Time after } \\
\text { stroke }\end{array}$ & $\begin{array}{l}\text { Patients } \\
\text { (active / } \\
\text { control) }\end{array}$ & Comments \\
\hline $\begin{array}{c}\text { Shyu } 2006 \\
(107)\end{array}$ & $\begin{array}{l}\text { Single-blind } \\
\text { controlled }\end{array}$ & $\begin{array}{c}15 \mu \mathrm{g} / \mathrm{kg} / \text { day s/c } \\
\text { For } 5 \text { days }\end{array}$ & Within 7 days & $7 / 3$ & $\begin{array}{l}\text { No thrombotic complications. } \\
\text { Improved outcome in G-CSF } \\
\text { group but a majority of } \\
\text { lacunar strokes }\end{array}$ \\
\hline $\begin{array}{l}\text { Sprigg } 2006 \\
\quad(106)\end{array}$ & $\begin{array}{c}\text { Double-blind } \\
\text { placebo-controlled }\end{array}$ & $\begin{array}{l}\text { Dose escalation } \\
1-10 \mu \mathrm{g} / \mathrm{kg} \mathrm{s} / \mathrm{c} \\
\text { For } 1 \text { or } 5 \text { days }\end{array}$ & $\begin{array}{l}\text { 7-30 days post } \\
\text { ictus }\end{array}$ & $24 / 12$ & $\begin{array}{c}\text { No difference in SAEs } \\
\text { although non-significant } \\
\text { increase in infection rates in } \\
\text { active group }\end{array}$ \\
\hline $\begin{array}{l}\text { Zhang } 2006 \\
\qquad(108)\end{array}$ & $\begin{array}{c}\text { Double-blind } \\
\text { placebo-controlled }\end{array}$ & $\begin{array}{l}2 \mu \mathrm{g} / \mathrm{kg} / \text { day s/c } \\
\text { For } 5 \text { days }\end{array}$ & Within 7 days & $15 / 45$ & $\begin{array}{l}\text { No difference in adverse } \\
\text { events reported. Significant } \\
\text { reduction in NIHSS }\end{array}$ \\
\hline
\end{tabular}

SAE serious adverse event; s/c subcutaneous; NIHSS National Institutes of Health Stroke Scale 